\title{
A IMPORTÂNCIA DA GESTÃO DE CUSTOS NA ELABORAÇÃO DO PREÇO DE VENDA
}

Irene Caires da Silva ${ }^{1}$, Tamires Fernanda Costa de Jesus, Tiago Pinheiro

${ }^{1}$ Docente da Universidade do Oeste Paulista - UNOESTE. ${ }^{2}$ Discente da Universidade do Oeste Paulista - UNOESTE

\section{RESUMO}

A Contabilidade de Custos tem sido fator essencial na tomada de decisões. Por meio de sua prática conseguimos formar o preço de venda de forma eficaz para que a saúde da empresa não seja afetada por não ter seus custos estabelecidos de acordo com sua necessidade. Partindo dessa premissa, este artigo tem como objetivo principal descrever os métodos da fixação de preço de venda e, em especial, aquele baseado nos custos incorridos. Como procedimentos metodológicos foram adotados a pesquisa bibliográfica, consistindo numa revisão da literatura existente em livros, monografia, dissertações, artigos científicos e materiais sobre o assunto em sites na Internet. Conclui-se que para obter lucros reais é necessário um estudo cauteloso de todos os custos incorridos para formar o preço de venda adequado e assim a empresa venha a obter sucesso no meio empresarial.

Palavras-chave: Gestão de custos; preço de venda; apuração dos custos e método de custeio.

\section{INTRODUÇÃO}

Contabilidade de Custos é a parte da ciência contábil que se dedica ao estudo racional dos gastos feitos para se obter um bem de venda ou de consumo, quer seja um produto, uma mercadoria ou um serviço. É o ramo da função financeira para determinar o lucro, para controlar as operações e para auxiliar o administrador no processo de tomada de decisão, visto a contabilidade ser um meio de ajudar a empresa a atingir seus objetivos.

Os objetivos desta pesquisa consistem em descrever alguns métodos de fixação de preço de venda; identificar os custos incorridos; verificar os gastos; e verificar como deve elaborar o preço de venda.

Como sabemos, o acompanhamento contábil de uma empresa gera informações importantes sobre o negócio empresarial, fornecendo subsídios adequados sobre seus custos e despesas. Dessa forma, esses esclarecimentos auxiliam no processo gerencial de uma organização melhorando a saúde financeira e econômica da organização.

E por fim, é de fundamental importância utilizar a gestão de custos, para tomada de decisões de uma empresa, que deverá encontrar o ponto de equilíbrio entre a produção e os custos fixos e variáveis para não incorrer em prejuízo, e conseguir alcançar a lucratividade desejada. 


\section{CONCEITO DE CONTABILIDADE DE CUSTOS}

O objetivo da contabilidade de custos é detalhar os custos e as despesas e a forma de atribuí-los a cada produto. Dessa forma, Santos (2006), aborda os objetivos como uma avaliação de ativos fabricados, apuração dos resultados, analise de rentabilidade, controle de operações, subsidio para formação de preço de venda além do subsidio para o planejamento da operação.

Assim, o sistema de custo é um instrumento gerencial que ajuda os gestores a tomar decisões em diversas situações, de modo a utilizar métodos diferenciados de acordo com a sua atividade.

Por fim utilizando a contabilidade de custos como instrumentos são capazes de suprir seus usuários com dados valiosos, de modo a colocá-los em condições de decidir sobre os destinos da entidade. Por isso, torna-se imprescindível conceituar e classificar os custos e seus sistemas, pois estes são diferentes de acordo com as finalidades.

\subsection{Finalidades da Contabilidade de Custos}

A Contabilidade de Custos ocupa-se da classificação, agrupamento, controle e atribuição dos custos, sendo que os custos coletados servem a três finalidades principais:

a) Fornecer dados de custos para a medição dos lucros e avaliação dos estoques.

b) Fornecer informações aos dirigentes para o controle das operações e atividades da empresa.

c) Fornecer informações para o planejamento da direção e a tomada de decisões.

Em resumo, a Contabilidade de Custos, fornece informações para a determinação do preço de venda dos produtos ou serviços.

Partindo dessa premissa esse artigo tratará de forma mais ampla a importância da gestão dos custos na formação do preço de venda dos produtos para a saúde estável e/ou lucrativa da empresa.

\subsection{Definições do preço de venda}

É muito importante que a definição do preço de venda leve em consideração todos os custos e despesas envolvidos na operação compra-venda. Para atingir seus objetivos, é indispensável que as empresas trabalhem com preços de venda competitivos e ao mesmo tempo lucrativos.

Segundo Martins (2003, P. 218): 
Para administrar preços de venda, sem dúvida é necessário conhecer o custo do produto; porém essa informação por si só, embora seja necessária, não é suficiente. Além do custo, é preciso saber o grau de elasticidade da demanda, os preços de produtos dos concorrentes, os preços de produtos substitutos, a estratégia de marketing da empresa, etc.; e tudo isso depende também do tipo de mercado em que a empresa atua, que vai desde o monopólio ou do monopsônio até a concorrência perfeita, mercado de commodities, etc.

A definição do preço de venda de um produto é fator determinante para o sucesso da empresa em um mercado competitivo. Porém, este é um assunto que causa muitas dúvidas aos empresários, principalmente os gestores que não tem muito conhecimentos sobre o assunto. $\mathrm{E}$, ao contrário do que muitos empreendedores pensam, a formação do preço de venda de um produto não é algo que pode ser criado de qualquer maneira, sem um conhecimento adequado.

Por isso, vamos analisar como definir o preço de venda dos produtos de uma empresa, considerando seus objetivos, pontos importantes a serem seguidos, problemas que podem ocorrer e também exemplos de formação de preço.

\subsection{Objetivos da fixação do preço de venda}

Estabelecer o preço de venda é um dos mais importantes momentos nas decisões a serem implantadas na empresa. A resposta a simples questão "Por quanto devem ser vendidas as mercadorias/produtos/serviços?" pode representar o sucesso, a rentabilidade, a competitividade ou não da empresa, e, consequentemente, sua existência ou não.

De acordo com Santos (2006), afirmar que, a fixação de preços de venda dos produtos e serviços é uma questão que afeta diariamente a vida de uma empresa, independentemente de seu tamanho, da natureza de seus produtos ou do setor econômico de sua atuação. Esta dificuldade de formar preço de venda pode atingir toda uma cadeia produtiva, desde o fornecedor da matéria-prima, passando pelo fabricante, distribuidores, varejistas até o consumidor final.

Portanto, torna-se fundamental ter conhecimento de como deve elaborar a fixação do preço de venda para obter sucesso empresarial.

\subsection{Método de Formação do Preço de Venda}

Na elaboração da formação do preço de venda existem vários métodos que podem ser utilizados. 
De acordo com Bianchi (2007, p.5), os métodos utilizados como auxílio na formação de venda podem ser:

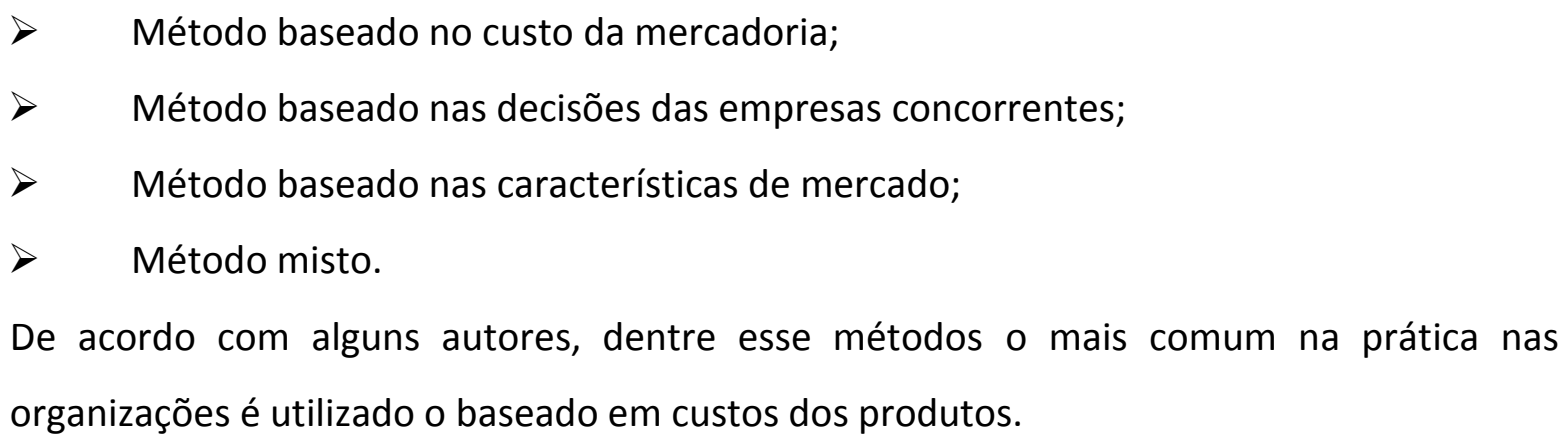

\subsection{Como formar o preço de venda?}

Além do aspecto financeiro, a definição do preço de venda deve levar em conta o aspecto mercadológico. O preço deverá estar próximo do praticado pelos concorrentes diretos da mesma categoria de produto e de qualidade. Também devem ser considerados o nível de conhecimento de marca, o tempo de mercado, o volume de vendas já conquistado e a agressividade da concorrência.

É preciso ter um bom planejamento, com metas claras de lucratividade e dimensionamento de capacidade de vendas;

Segundo Martins (2003, P. 218) ".os preços podem ser fixados: com base nos custos, com base no mercado ou com base numa combinação de ambos".

Desse modo, na elaboração da formação do preço de venda não poderá levar em consideração apenas os fatores internos, mas também se deve observar os fatores externos que possam interferir no processo de formação do preço de venda..

\section{METODOLOGIA}

Para a realização desta pesquisa utilizou-se um levantamento bibliográfico, onde buscamos informações em livros, artigos científicos, monografia, dissertações e sites oficiais, entre outros.

De acordo com Gil (2010, p.29), “a pesquisa bibliográfica com base em material já publicado".

Dessa forma, o método utilizado permitiu que se conhecesse assuntos ligados diretamente na construção de conhecimentos de custos mais elaborados, mais sistemáticos demonstrando a importância da metodologia para as pesquisas científicas. 
Desse modo, a pesquisa se enquadra também de natureza qualitativa é um conceito que abrange várias formas de estudo ajudando a compreender e explicar o conhecimento adquirido.

Discutimos a metodologia do trabalho científico buscando responde dúvida existentes antes do estudo, procurando conhecer um universo de significados, motivos, aspirações e valores em relação a contabilidade de custos

Portanto, essa pesquisa é de abordagem qualitativa, onde utilizou resgate bibliográfico, pois temos como objetivo analisar as informações, estudando cada aspecto que envolva a Contabilidade de Custos aplicada na empresa para melhor desempenho da lucratividade.

\section{CONCLUSÃO}

Este artigo teve como objetivo maior demonstrar uma das varias aplicações da Contabilidade de Custos, como forma de auxílio na tomada de decisões em um ponto que é de primordial importância para consolidação de qualquer empreendimento, que é a formação do preço de venda.

Sendo assim, observa-se que nenhuma decisão deve ser tomada observando apenas fatos isolados, ou seja, para que se possa definir qual o melhor caminho a ser seguido, é necessário,

utilizar dos benefícios proporcionados pela Contabilidade de Custos, aliados a observação das diversas variáveis que exercem influência nas diretrizes da organização.

Nota-se que apesar das limitações o conhecimento dos custos para uma empresa é fator importante para sua sobrevivência, pois nenhuma empresa independente do seu porte sobrevive por muito tempo se praticar preços de venda abaixo de seus custos.

E, tão importante quanto saber determinar os custos dos produtos fabricados ou dos serviços prestados, é saber otimizar esses custos, estudando técnicas que proporcionem a redução destes sem, no entanto, reduzir a qualidade dos mesmos. Sendo esse procedimento de elaboração do preço de venda de um produto um desafio para a Contabilidade de Custos.

\section{REFERÊNCIAS BIBLIOGRÁFICAS}

BERNARDI, Luiz Antônio. Política e Formação de Preços: Uma Abordagem Competitiva Sistêmica e Integrada - 2. ed.- São Paulo: Atlas, 1998.

CREPALDI, Silvio Aparecido. Curso Básico de Contabilidade de Custos. 4. Ed. São Paulo: Editora Atlas S.A, 2009.

MARTINS, Eliseu. Contabilidade de Custos. 9 Edição. São Paulo: Editora Atlas S.A, 2003. 
Encontro de Ensino, Pesquisa e Extensão, Presidente Prudente, 21 a 24 de outubro, 2013

MEGLIORINI, Evandir. Custos. São Paulo: Makron Books, 2001.

GIL, Antonio Carlos. Como Elaborar Projetos de Pesquisa. - 5. Ed - São Paulo: Atlas, 2010.

SANTOS, J. L.; ET. AL. Fundamentos de Contabilidades de Custos. São Paulo: Atlas, 2006. 